\title{
A supplement containing multiple types of gluconeogenic substrates alters intake but not productivity of heat-stressed Afshari lambs ${ }^{1}$
}

\author{
E. Mahjoubi, ${ }^{* 2}$ H. Amanlou, * M. Hossein Yazdi,* \\ N. Aghaziarati,* G. R. Noori,* C. I. Vahl, $\uparrow$ B. J. Bradford, $\$$ and L. H. Baumgard $§$ \\ *Department of Animal Science, University of Zanjan, Zanjan, Iran 45371-38791; † Department \\ of Statistics, Kansas State University, Manhattan 66506; \$Department of Animal Sciences and Industry, \\ Kansas State University, Manhattan 66506; and §Department of Animal Science, Iowa State University, Ames 50011
}

\begin{abstract}
Thirty-two Afshari lambs were used in a completely randomized design with a $2 \times 2$ factorial arrangement of treatments to evaluate a nutritional supplement designed to provide multiple gluconeogenic precursors during heat stress (HS). Lambs were housed in thermal neutral (TN) conditions and fed ad libitum for $8 \mathrm{~d}$ to obtain covariate data (period 1 [P1]) for the subsequent experimental period (period 2 [P2]). During P2, which lasted $9 \mathrm{~d}$, half of the lambs were subjected to HS and the other 16 lambs were maintained in TN conditions but pair fed (PFTN) to the HS lambs. Half of the lambs in each thermal regime were fed (top-dressed) $100 \mathrm{~g} / \mathrm{d}$ of a feed supplement designed to provide gluconeogenic precursors (8 lambs in HS [heat stress with Glukosa $\{\mathrm{HSG}\}$ ] and 8 lambs in PFTN [pair-fed thermal neutral with Glukosa]) and the other lambs in both thermal regimes were fed only the basal control diet (HS without Glukosa [HSC] and pair-fed thermal neutral without Glukosa). Heat stress decreased DMI (14\%) and by design there were no differences between the thermal treatments, but HSG lambs had increased DMI $(7.5 \% ; P<0.05)$ compared with the HSC lambs. Compared with PFTN lambs,
\end{abstract}

rectal temperature and skin temperature at the rump, shoulder, and legs of HS lambs were increased $(P<$ $0.05)$ at 0700 and $1400 \mathrm{~h}$. Rectal temperature at $1400 \mathrm{~h}$ decreased for HSG lambs $\left(0.15 \pm 0.03^{\circ} \mathrm{C} ; P<0.05\right)$ compared with HSC lambs. Despite similar DMI between thermal treatments, ADG for HS and PFTN lambs in P2 was decreased 55 and $85 \%$, respectively, compared with lambs in P1 $(P<0.01)$. Although the prefeeding glucose concentration was not affected by thermal treatment or diet, HSG lambs had increased postfeeding glucose concentration compared with HSC lambs $(P<0.05)$. In contrast to the glucose responses, circulating insulin was influenced only by thermal treatment; HS lambs had increased insulin concentration $(P<0.01)$ before feeding and decreased concentration $(P<0.05)$ after feeding compared with PFTN lambs. Heat-stressed lambs had decreased NEFA concentration before feeding $(P<0.01)$ but not after feeding relative to PFTN lambs. Although this nutritional strategy did not affect ADG, the lower rectal temperature in HSG lambs indicates that dietary inclusion of a mixture of glucogenic precursors can potentially benefit animal health during HS.

Key words: Afshari lamb, average daily gain, glucose precursor, heat stress

(C) 2016 American Society of Animal Science. All rights reserved.

J. Anim. Sci. 2016.94:2497-2505 doi:10.2527/jas2015-9697

\footnotetext{
${ }^{1}$ The authors gratefully appreciate S. S. Mousavi Zanjani, O. Afsarian, D. Zahmatkesh, V. Gholami, and the staff of Experimental Farm in University of Zanjan for their assistance in carrying out of this experiment. We thankfully acknowledge Moafi for providing us with Glukosa. Also, we thank F. Elahian, M. Mohseni, and staff of Faculty of Pharmacy, Zanjan University of Medical Sciences, for helping us to do ELISA measurements.

${ }^{2}$ Corresponding author: e_mahjoubi@znu.ac.ir; e_mahjoubi133@yahoo.com

Received August 19, 2015.

Accepted April 6, 2016.
}

\section{INTRODUCTION}

Heat stress (HS) is a global problem that threatens efficient animal production (West, 1999; Bernabucci et al., 2010). Its economic impact on animal agriculture worldwide is staggering, and identifying strategies to minimize the negative effects of current and future climate change on the production of high-quality animal protein for human consumption is critical (Baumgard and Rhoads, 2013). 
Among the potential approaches to alleviate HS, such as physical modifications to the environment, management adaptations, genetic selection, and dietary modifications, nutritional strategies are among the easiest and cheapest to implement. Nutritional tactics used during HS generally focus on enhancing the energy density of the diet and decreasing the thermic effect of feeding (West, 1999; Kadzere et al., 2002). Recently, studies have demonstrated that heat-stressed farm animals, including growing and lactating ruminants, preferentially utilize glucose for processes other than milk and muscle synthesis during HS (Baumgard and Rhoads, 2012, 2013). One method of enhancing hepatic glucose efflux is to feed additional starch, but feeding excessive grain increases the risk of rumen acidosis (Kadzere et al., 2002). As a result, safely providing substrates that are gluconeogenic themselves or are metabolized into glucose precursors (propionate) may increase productivity or production efficiency during the summer (Baumgard and Rhoads, 2012).

We hypothesized that supplementing a product containing gluconeogenic precursors could increase circulating glucose during HS and improve animal performance. Therefore, study objectives were to evaluate the effects of a supplement containing glucose precursors on productive performance and blood metabolite concentrations in Afshari lambs during HS.

\section{MATERIAL AND METHODS}

\section{Animals and Experimental Design}

Lambs were cared for according to the guidelines of the Iranian Council of Animal Care (1995; for sheep). Thirty-two intact 2- to 2.5-mo-old growing male Afshari lambs $(41.0 \pm 4.6 \mathrm{~kg} \mathrm{BW})$ were selected and housed in individual stalls $(2$ by $1 \mathrm{~m}$, with individual feeders and waters) $2 \mathrm{wk}$ before the start of the experiment, as we have previously described (Mahjoubi et al., 2015). Afshari is a medium-sized, coarse-wool Iranian breed, reared primarily for meat, that originated from a warm environment (Terrill and Slee, 1991). Feed was delivered as a total mixed ration at 0800 and $1430 \mathrm{~h}$, primarily consisting of alfalfa hay, ground corn grain, and soybean meal, with a dietary forage-to-concentrate ratio of 67.5:32.5. Half of the ration was provided at each feeding, and the diet was formulated to meet or exceed NRC (2007) recommendations (Table 1) using the Small Ruminant Nutrition System (Tedeschi et al., 2010; version 1.9.4468). During this experiment, the wool length was between 30 and $35 \mathrm{~mm}$. This trial consisted of 2 experimental periods, both with a 15.5- and 8.5-h light/ dark cycle. Period 1 (P1) lasted $8 \mathrm{~d}$, with all of the lambs in a thermal neutral (TN) condition $\left(22.2 \pm 3.1^{\circ} \mathrm{C}\right.$ and a
Table 1. Ingredients and chemical composition of diet $(\mathrm{DM} \text { basis })^{1}$

\begin{tabular}{lr}
\hline \hline Item & Percent \\
\hline Alfalfa hay & 32.50 \\
Ground barley grain & 5.48 \\
Ground corn grain & 42.00 \\
Fish meal & 2.75 \\
Soybean meal & 14.00 \\
Sodium bicarbonate & 1.19 \\
Salt & 0.60 \\
Calcium carbonate & 0.60 \\
Mineral-vitamin permix ${ }^{2}$ & 0.88 \\
Chemical composition & \\
DM & 89.74 \\
ME ${ }^{3}$ Mcal/kg & 2.49 \\
CP & 15.90 \\
NDF & 29.00 \\
ADF & 17.90 \\
Crude fat & 3.30 \\
\hline
\end{tabular}

${ }^{1}$ Composition of the basal diet to which $100 \mathrm{~g}$ of Glukosa (Novation Co., Madrid, Spain) was added as a top-dress. Glukosa contained $330 \mathrm{~g} / \mathrm{kg}$ of glycerol, $94.5 \mathrm{~g} / \mathrm{kg}$ of mono propylene glycol, $70.5 \mathrm{~g} / \mathrm{kg}$ of calcium propionate, $470 \mathrm{mg} / \mathrm{kg}$ of niacin, and $185 \mathrm{mg} / \mathrm{kg}$ of cobalt sulfate. Effective material was $49.5 \%$ and the rest of material was wheat bran as a carrier.

${ }^{2}$ Provided (per kg of DM) 700,000 IU vitamin A, 600,000 IU vitamin D, 1,000 mg vitamin E, 1,000 mg monensin, $250 \mathrm{~g} \mathrm{Ca}, 200 \mathrm{~g} \mathrm{Mg}, 8 \mathrm{mg} \mathrm{Co}$, $800 \mathrm{mg} \mathrm{Cu}, 40 \mathrm{mg} \mathrm{I}, 3,200 \mathrm{mg} \mathrm{Mn}, 10 \mathrm{mg} \mathrm{Se}$, and 3,000 mg Zn.

${ }^{3}$ Estimated using the Small Ruminant Nutrition System (Tedeschi et al., 2010; version 1.9.4468) individual dietary ingredients.

temperature-humidity index [THI $]$ of $67.9 \pm 3.2$; Fig. 1). Period 2 (P2) lasted $9 \mathrm{~d}$; half of the lambs $(n=16)$ were subjected to cyclical HS conditions $\left(33.0\right.$ to $45.0^{\circ} \mathrm{C}$ and a THI of more than 80 for $24 \mathrm{~h} / \mathrm{d}$ and more than 90 for $8 \mathrm{~h} / \mathrm{d}$ ) and the other lambs continued in TN conditions but were pair fed (PFTN) to eliminate the confounding effects of unequal nutrient intake, as we have previously described (Mahjoubi et al., 2014). The PFTN group began P2 $3 \mathrm{~d}$ after the HS lambs to calculate and implement feed intake reductions. Half of the lambs in each thermal environment ( 8 lambs in the HS group and 8 lambs in the PFTN group) were fed $100 \mathrm{~g} / \mathrm{d}$ of a product designed to provide a mixture of glucose precursors (GLU; Glukosa; Novation Co., Madrid, Spain) as a topdress only in the morning feeding. Glukosa contained glycerol (330 g/kg), mono propylene glycol $(94.5 \mathrm{~g} /$ $\mathrm{kg})$, calcium propionate $(70.5 \mathrm{~g} / \mathrm{kg})$, niacin $(470 \mathrm{mg} /$ $\mathrm{kg})$, and cobalt sulfate $(185 \mathrm{mg} / \mathrm{kg})$ and colloidal silica as the carrier. For GLU-fed PFTN lambs (pair-fed thermal neutral with Glukosa [PFTNG]), $100 \mathrm{~g}$ of calculated feed offered was substituted with GLU, whereas for HS lambs (heat stress with Glukosa [HSG]), 100 g GLU was added to their feed. Metabolizable energy ( 2.53 vs. $2.49 \mathrm{Mcal} / \mathrm{kg} \mathrm{DM}$ ) and CP (15.76 vs. $15.90 \%$ of DM) concentrations of control and GLU diets, respectively, were similar. Both pair-fed thermal neutral 


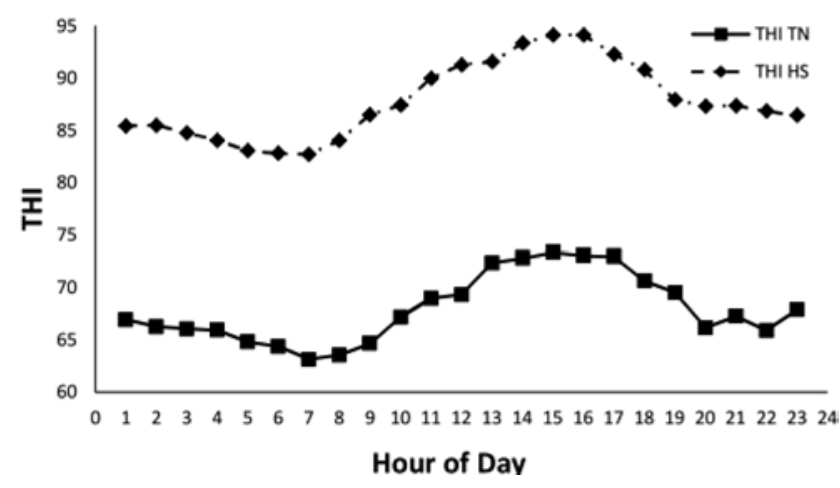

Figure 1. Average diurnal patterns of temperature-humidity index (THI) during thermal neutral (TN) or heat stress (HS) conditions.

without Glukosa (PFTNC) and PFTNG lambs were fed based on the mean percentage decrease in DMI of all HS lambs in P2 compared with HS lambs in P1.

All production and blood data were collected daily through both experimental periods. The THI was calculated using the following equation: THI $=[0.8 \times$ ambient temperature $\left.\left({ }^{\circ} \mathrm{C}\right)\right]+[(\%$ relative humidity $/ 100) \times$ (ambient temperature - 14.4)] + 46.4 (Buffington et al., 1981). The dimensions of both the HS and TN barns were 4 by 10 by $3 \mathrm{~m}$. Three thermostat-regulated heaters were used to generate the heat load and 2 fans were used to minimize heat gradients within the room. The $\mathrm{TN}$ room was equipped with air conditioning.

\section{Measurements}

Dry matter intake and water intake were recorded daily in each period. Heat stress indices were obtained from all animals at 0700 and $1400 \mathrm{~h}$ daily and included rectal temperature (RT; PIC Vedodigit II, Digital Thermometer; Pic Solution Co., Como, Italy; with \pm $0.1^{\circ} \mathrm{C}$ accuracy) and respiration rate (recorded by counting the flank movements). Shaved skin temperature at the shoulder, rump, and rear and front leg was measured using an infrared temperature gun (model MiniTemp MT6; Raytek Corp., Santa Cruz, CA). Body weight was recorded at the beginning and end of both periods and the difference was divided by the days within period to compute ADG.

Two data loggers (MASTECH, model MS-6505; MASTECH, Taipei, Taiwan) continuously recorded the temperature and humidity data in 15-min intervals. The data loggers were suspended at a height of approximately $1 \mathrm{~m}$ above the floor (approximate lamb wither height) for the duration of the experiment. The ambient temperature was controlled, but humidity was not.

\section{Metabolite and Hormone Assays}

Jugular vein blood (5 $\mathrm{mL}$ in vacutainer tubes containing 200 United States Pharmacopeia units of sodium heparin) was obtained prior to morning feeding and $4 \mathrm{~h}$ after that on $\mathrm{d} 2,5$, and 8 in P1 and d 2, 5, 7, and 9 in P2, as previously described (Mahjoubi et al., 2014, 2015). Blood samples were placed on ice and, within $25 \mathrm{~min}$ of collection (Russell and Roussel, 2007), centrifuged at $2,000 \times g$ for $15 \mathrm{~min}$ at room temperature to harvest plasma, which was stored at $-20^{\circ} \mathrm{C}$ for later analysis. Plasma glucose (GOD-PAR; Pars Azmun Laboratory, Tehran, Iran), blood urea nitrogen (BUN; BUN assay kit; Pars Azmun Laboratory), and NEFA concentrations (NEFA-HR(2) assay kit; Wako Chemicals GmbH, Neuss, Germany) were determined using commercially available kits. Analyses were performed using a BT 1500 automatic biochemistry analyzer (Biotechnica Instruments S.p.A, Rome, Italy), which simultaneously completed all the aforementioned diagnostic tests. Insulin concentrations were determined with an ELISA kit (Mercodia Ovine Insulin ELISA; Mercodia AB, Uppsala, Sweden). The assay was conducted in 96-well microplates and read at $450 \mathrm{~nm}$ using the Infinite M200 microplate reader (TECAN Group Ltd., Männedorf, Switzerland). Plasma insulin concentrations were analyzed in duplicate from samples obtained on d 5 and 8 of $\mathrm{P} 1$ and $\mathrm{d} 2,7$, and 9 of $\mathrm{P} 2$ from 24 lambs (6 lambs per treatment were randomly selected for the whole study). Inter- and intra-assay coefficients for the plasma insulin assay were 4.3 and $4.8 \%$, respectively. To indirectly evaluate insulin sensitivity, a revised quantitative insulin sensitivity check index (RQUICKI) was calculated for prefeeding samples according the equation suggested by Holtenius and Holtenius (2007): RQUICKI = $1 /[\log$ (glucose in $\mathrm{mg} / \mathrm{dL}$ ) $+\log$ (insulin in microunits/ $\mathrm{mL})+\log (\mathrm{NEFA}$ in $\mathrm{mmol} / \mathrm{L})]$.

\section{Statistical Analysis}

All recorded data in P1 for production, thermal indices, and blood parameters were condensed into a single average and used as a covariate, represented as $d-1$ on the figures. Statistical analyses were performed using the MIXED procedure of SAS (version 9.1; SAS Inst. Inc., Cary, NC) to evaluate the fixed effects of the respective P1 covariate, environment, diet, day (of P2), and their interactions, with lamb as a random effect. Repeated measurements over time (DMI, water intake, body temperature indices, and blood metabolites) for each lamb were assessed with an autoregressive covariance structure and day as the repeated effect. Data were reported as least squares means and effects were considered significant if $P<$ 0.05 and were declared a tendency if $P<0.1$. 


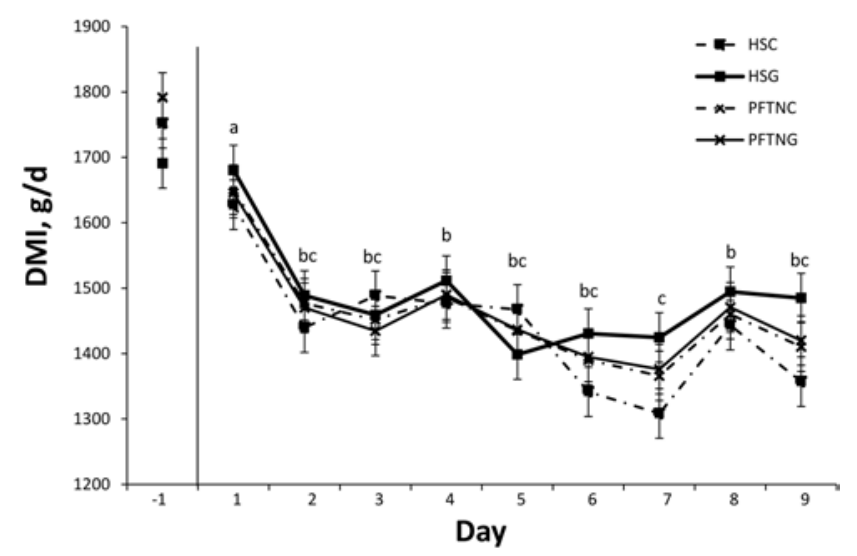

Figure 2. Effects of heat stress and pair feeding as well as offering a glucose precursor (Glukosa; Novation Co., Madrid, Spain) on DMI in growing Afshari lambs (HSC = heat stress without Glukosa; HSG = heat stress with Glukosa; PFTNC = pair-fed thermal neutral without Glukosa; PFTNG $=$ pair-fed thermal neutral with Glukosa). The vertical line separates covariate period (thermal neutral conditions and ad libitum feed intake) from period 2 (either heat stress conditions and ad libitum feed intake or thermal neutral conditions and pair fed). A day effect was detected during period 2. ${ }^{\mathrm{a}-\mathrm{c}}$ Superscripts show differences among days $(P<0.05)$. Each point represents least squares means $\pm \mathrm{SE}$.

\section{RESULTS}

\section{Intake and Body Parameters}

During P1, all lambs were housed in TN conditions and there were no differences in DMI between groups (Fig. 2). However, HS reduced DMI by approximately $14 \%$, on average $(P<0.01)$, compared with P1. Because PFTN lambs were fed based on the overall percentage decrease in DMI of HS lambs from the average DMI during P1, DMI was not different between them (PFTN and PFTNG lambs), although the environment $\times$ diet interaction was significant $(P<0.05$; Table 2); HSG lambs had increased intake (approximately 6.5\%) compared with the HS without Glukosa (HSC) group. As expected, water intake increased during P2 for HS lambs (approximately 20\%; $P<0.01)$ but was not influenced by diet. Although ADG was similar across groups during P1 (463 vs. $492 \mathrm{~g} / \mathrm{d}$ for TN and HS groups, respectively), ADG decreased $(P<0.01)$ during P2 $(55$ and $85 \%$ for HS and PFTN lambs, respectively) compared with P1. Heat stress lambs gained approximately $400 \%$ more than PFTN lambs during P2. Neither diet nor the environment $\times$ diet interaction affected $\mathrm{ADG}$.

As expected, all body temperature parameters measured at 0700 and $1400 \mathrm{~h}$ were increased in the HS lambs $(P<0.01$; Table 2$)$ compared with PFTN controls. There tended to be an environment $\times$ diet interaction $(P=$ 0.08 ) for the $1400 \mathrm{~h} \mathrm{RT}$, with lower RT observed in HSG lambs than in $\mathrm{HSC}$ lambs $\left(0.15 \pm 0.04^{\circ} \mathrm{C}\right)$. Respiratory rate was increased 400 and $500 \%(P<0.01)$ at 0700 and
1400 h, respectively, for HS lambs compared with PFTN lambs. Regardless of measurement time, overall shaved skin temperature at the rump and the shoulder were increased by 11 and $13 \%(P<0.01)$, respectively, in the HS group compared with the PFTN group, and diet did not influence these measures (Table 2).

Although neither environment nor diet influenced prefeeding plasma glucose concentration (Table 3), postfeeding glucose concentration was increased in HSG lambs compared with HSC lambs. The environment $x$ diet interaction was due to hypoglycemia in HSC lambs $(P<0.01)$, and there was no difference between HSG lambs and PFTN lambs (Table 3). Regardless of environment, prefeeding BUN concentration was decreased in GLU-fed lambs $(P<0.03)$ and there was no effect of diet or environment on postfeeding BUN (Table 3). Environment, but not diet, influenced circulating insulin (Fig. 3); prefeeding insulin concentration was increased $(P<0.01)$ in HS lambs whereas postfeeding insulin was increased $(P<0.05)$ in PFTN lambs. There was a day $\times$ environment interaction $(P<0.05)$ for prefeeding insulin concentration, with progressive decreases in PFTN lambs compared with HS lambs as P2 advanced (Fig. 3). Although neither diet nor environment affected postfeeding circulating NEFA, PFTN lambs had increased prefeeding NEFA compared with HS lambs (Fig. 4; $P<0.01$ ). There was an environment $\times$ day interaction $(P<0.01)$ for postfeeding plasma NEFA concentration, driven by an increase in NEFA on d 5 followed by a decrease on $\mathrm{d} 7$ and 9 in PFTN lambs (Fig. 4). Based on RQUICKI, PFTN lambs were more sensitive to insulin compared with HS groups ( 0.59 vs. $0.48 \pm 0.03 ; P<0.01)$. An environment $\times$ day interaction $(P<0.03)$ indicated that prefeeding responsiveness to insulin was gradually increased in PFTN lambs.

\section{DISCUSSION}

Heat stress negatively affects many (if not all) aspects of animal agriculture and is one of the largest barriers to efficient farm animal production. Although substantial advances have been achieved in heat abatement technologies, animal performance remains compromised during the summer. Consequently, due to its ease of implementation and limited costs, dietary supplementation may be an attractive strategy to ameliorate economic losses due to HS. Recent data in both monogastric and ruminant farm animals demonstrate that the preferred fuel of peripheral tissues during HS is glucose (see review by Baumgard and Rhoads, 2013). Modifying the postabsorptive glucose status in ruminants, however, is challenging because ingested carbohydrates are primarily fermented to short-chain fatty acids in the rumen. As a result, ruminants rely almost 
Table 2. Effects of a commercial glucose precursor during heat stress and pair feeding on production, heat stress variables, and blood metabolites in growing Afshari lambs

\begin{tabular}{|c|c|c|c|c|c|c|c|c|c|c|c|}
\hline \multirow[b]{2}{*}{ Variable $^{1}$} & \multirow[b]{2}{*}{$\mathrm{P} 1^{2}$} & \multicolumn{4}{|c|}{ Treatments $^{3}$} & \multirow[b]{2}{*}{ SEM } & \multicolumn{5}{|c|}{$P$-value ${ }^{4}$} \\
\hline & & HSC & HSG & PFTNC & PFTNG & & Env & Trt & Trt $\times$ Env & Trt $\times$ day & Env $\times$ day \\
\hline DMI, kg/d & $1,746.6$ & $1,427.8^{\mathrm{b}}$ & $1,536.0^{\mathrm{a}}$ & $1,453.5^{\mathrm{b}}$ & $1,459.5^{\mathrm{b}}$ & 24.32 & 0.30 & 0.02 & 0.05 & 0.38 & $<0.01$ \\
\hline WI, kg/d & 6.66 & 8.13 & 8.51 & 6.87 & 6.49 & 0.30 & $<0.01$ & 0.98 & 0.22 & 0.77 & $<0.01$ \\
\hline WI:DMI & 3.81 & 5.74 & 5.59 & 4.74 & 4.57 & 0.21 & $<0.01$ & 0.46 & 0.96 & 0.34 & $<0.01$ \\
\hline $\mathrm{ADG}, \mathrm{g} / \mathrm{d}$ & 478.5 & 210.0 & 233.5 & 75.6 & 60.7 & 49.97 & $<0.01$ & 0.93 & 0.85 & - & - \\
\hline $\mathrm{G}: \mathrm{F}$ & 0.27 & 0.14 & 0.16 & 0.05 & 0.04 & 0.03 & $<0.01$ & 0.97 & 0.72 & - & - \\
\hline \multicolumn{12}{|c|}{$0700 \mathrm{~h}$ body temperature indices } \\
\hline $\mathrm{RR}, \mathrm{bpm}$ & 43.3 & 82.2 & 91.9 & 28.2 & 28.8 & 3.78 & $<0.01$ & 0.20 & 0.22 & 0.35 & $<0.01$ \\
\hline $\mathrm{RT},{ }^{\circ} \mathrm{C}$ & 39.3 & 39.49 & 39.44 & 39.10 & 39.20 & 0.04 & $<0.01$ & 0.48 & 0.16 & 0.41 & 0.06 \\
\hline $\mathrm{T}_{\mathrm{R}},{ }^{\circ} \mathrm{C}$ & 35.2 & 37.44 & 37.54 & 33.20 & 32.87 & 0.15 & $<0.01$ & 0.44 & 0.17 & 0.13 & $<0.01$ \\
\hline $\mathrm{T}_{\mathrm{S}},{ }^{\circ} \mathrm{C}$ & 35.6 & 37.53 & 37.20 & 33.50 & 33.33 & 0.26 & $<0.01$ & 0.34 & 0.75 & 0.22 & 0.39 \\
\hline $\mathrm{T}_{\mathrm{FL}},{ }^{\circ} \mathrm{C}$ & 33.7 & 35.97 & 36.36 & 29.04 & 29.66 & 0.28 & 0.03 & 0.08 & 0.68 & 0.29 & $<0.01$ \\
\hline $\mathrm{T}_{\mathrm{RL}},{ }^{\circ} \mathrm{C}$ & 34.2 & 36.29 & 36.75 & 30.89 & 30.78 & 0.25 & $<0.01$ & 0.49 & 0.25 & 0.12 & $<0.01$ \\
\hline \multicolumn{12}{|c|}{$1400 \mathrm{~h}$ body temperature indices } \\
\hline RR, bpm & 62.2 & 166.0 & 176.1 & 38.33 & 46.15 & 6.41 & $<0.01$ & 0.17 & 0.78 & 0.70 & $<0.01$ \\
\hline $\mathrm{RT},{ }^{\circ} \mathrm{C}$ & 39.4 & $40.01^{\mathrm{a}}$ & $39.86^{\mathrm{b}}$ & $39.34^{\mathrm{c}}$ & $39.34^{\mathrm{c}}$ & 0.03 & $<0.01$ & 0.09 & 0.08 & 0.05 & 0.02 \\
\hline $\mathrm{T}_{\mathrm{R}}{ }^{\circ} \mathrm{C}$ & 37.0 & 41.42 & 41.34 & 35.79 & 35.70 & 0.15 & $<0.01$ & 0.58 & 0.72 & $<0.01$ & $<0.01$ \\
\hline $\mathrm{T}_{\mathrm{S}},{ }^{5}{ }^{\circ} \mathrm{C}$ & 37.1 & 40.98 & 40.98 & 35.96 & 35.97 & 0.13 & $<0.01$ & 0.61 & 0.98 & 0.02 & $<0.01$ \\
\hline $\mathrm{T}_{\mathrm{FL}}{ }^{\circ} \mathrm{C}$ & 35.7 & 39.64 & 39.68 & 33.61 & 34.00 & 0.20 & $<0.01$ & 0.22 & 0.38 & 0.14 & $<0.01$ \\
\hline $\mathrm{T}_{\mathrm{RL}}{ }^{\circ} \mathrm{C}$ & 35.8 & 39.72 & 39.80 & 34.07 & 34.30 & 0.17 & $<0.01$ & 0.36 & 0.67 & $<0.01$ & $<0.01$ \\
\hline
\end{tabular}

${ }^{\mathrm{a}-\mathrm{c}}$ Means within a row with different superscripts $\operatorname{differ}(P<0.05)$.

${ }^{1} \mathrm{WI}=$ water intake; $\mathrm{RR}=$ respiration rate; bpm $=$ breaths per minute; $\mathrm{RT}=$ rectal temperature; $\mathrm{T}_{\mathrm{R}}=$ rump temperature; $\mathrm{T}_{\mathrm{S}}=$ shoulder temperature; $\mathrm{T}_{\mathrm{FL}}=$ front leg temperature; $\mathrm{T}_{\mathrm{RL}}=$ rear leg temperature.

${ }^{2} \mathrm{P} 1$ = period 1 . Values in this column are average values for each item during P1.

${ }^{3} \mathrm{HSC}=$ heat stress without Glukosa (Novation Co., Madrid, Spain); HSG = heat stress with Glukosa; PFTNC = pair-fed thermal neutral without Glukosa; PFTNG = pair-fed thermal neutral with Glukosa.

${ }^{4}$ All parameters were significant for day. Env = environment; Trt $=$ treatment.

${ }^{5} \mathrm{Trt} \times$ Env $\times$ day was significant only for this parameter.

Table 3. Effects of a commercial glucose precursor during severe heat stress (HS) and pair feeding on HS variables and blood metabolites in growing Afshari lambs

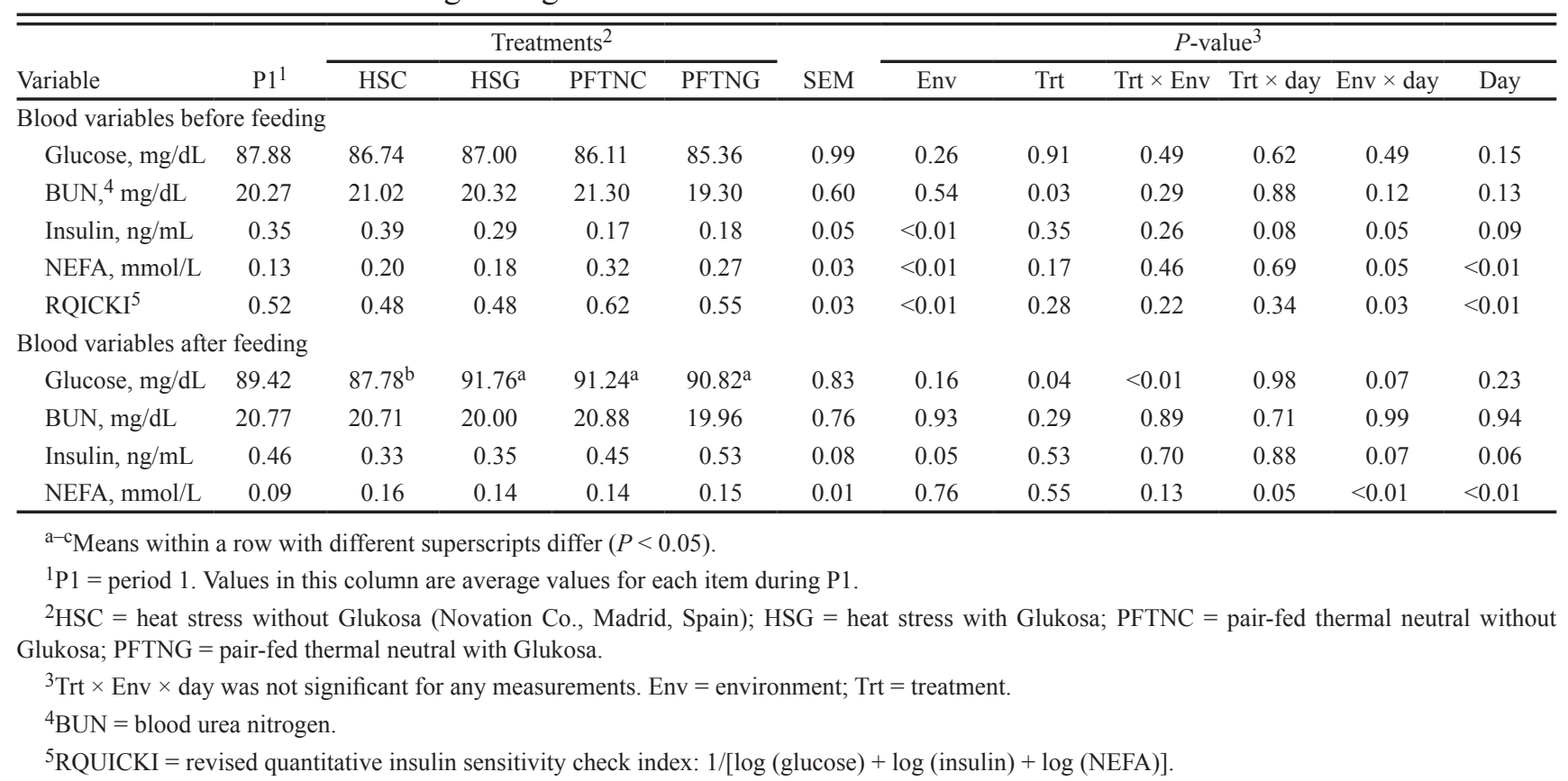



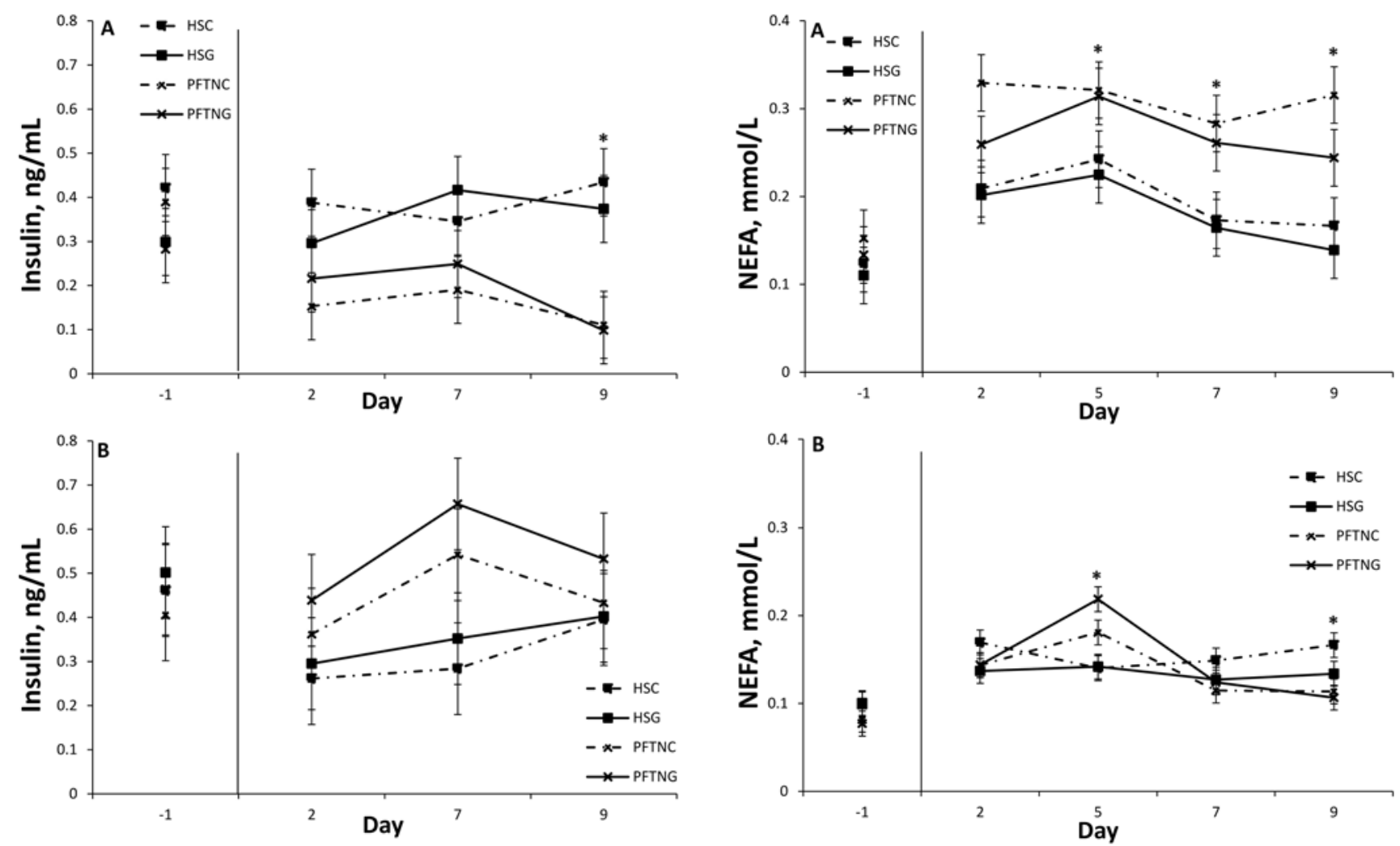

Figure 3. Effects of heat stress and pair feeding as well as offering a glucose precursor (Glukosa; Novation Co., Madrid, Spain) on prefeeding (A) or postfeeding (B) insulin concentrations in growing Afshari lambs ( $\mathrm{HSC}=$ heat stress without Glukosa; HSG $=$ heat stress with Glukosa; PFTNC $=$ pair-fed thermal neutral without Glukosa; PFTNG $=$ pair-fed thermal neutral with Glukosa). There was an environment $\times$ day interaction and the symbol $(*)$ shows differences $(P<0.05)$ on the relevant day. Each point represents least squares means $\pm \mathrm{SE}$.

exclusively on gluconeogenesis to meet their glucose requirements (Aschenbach et al., 2010). When ruminants are in a positive energy balance, propionate is the major substrate for gluconeogenesis, and it mostly originates from starch fermentation (Huntington, 1990). As a result, dietary grain content is typically increased during HS to maximize hepatic glucose output. Unfortunately, heat-stressed ruminants are predisposed to ruminal acidosis for a variety of biological, managerial, and behavioral reasons, so feeding additional concentrates needs to be carefully considered (Kadzere et al., 2002). Identifying alternative feeding strategies that can safely enhance hepatic glucose output may be an effective strategy to maximize production during HS.

By experimental design, the pattern and magnitude of feed intake reduction was similar between the HS lambs and the PFTN controls. However, HSG lambs consumed more DM than HSC lambs. In contrast with this experiment, we failed to detect any DMI response to GLU during HS in our previous study (Hossein Yazdi et al., 2015) with Holstein bull calves fed the same product. Understanding the mechanism or mechanisms underlying this increase in DMI is very important. Ostensibly,

the intraruminal metabolic fate of most of the components in the supplement is propionate. According to the hepatic oxidation theory (Allen et al., 2005), when glucose demand is high (e.g., early lactation and HS), providing the liver with propionate results in increased gluconeogenesis, in turn enhancing hepatocyte ATP consumption and increasing DMI. Nevertheless, there are inconsistencies within the literature on how glycerol affects feed intake in ruminants (DeFrain et al., 2004; Bodarski et al., 2005; Boyd et al., 2013). Our results suggest that GLU have some distinct effect on DMI during HS, which should be addressed by further experiments.

In contrast to our expectations, HS lambs actually outgained (approximately 430\%) the PFTNC lambs on a similar plane of nutrition. Also, the increased DMI in HSG lambs did not translate to enhanced ADG. Increased growth of HS lambs compared with PFTN lambs agrees with our recent findings (Mahjoubi et al., 2015) and is in contrast with our first report with the same breed and diet (Mahjoubi et al., 2014). Although it was not measured, an increase in activity energy expenditure in the PFTN lambs could, in part, explain this observation (the PFTN lambs were visibly anxious). 
Furthermore, the fact that heat-stressed sheep grew faster than the pair-fed controls agrees with recent pig experiments (Sanz-Fernandez et al., 2012, 2015; Pearce et al., 2013). This growth differential is even more energetically atypical considering that HS is thought to increase maintenance costs in most animals (Kleiber, 1961) including sheep (Ames et al., 1971). Based on the equations used in the Small Ruminant Nutrition System (Tedeschi et al., 2010; version 1.9.4468), maintenance requirements in our lambs were about $3.6 \mathrm{Mcal} / \mathrm{d}$, and based on their DMI, they should have gained approximately $19 \mathrm{~g} / \mathrm{d}$, much less than the actual ADG in both the HS (224 g/d) and the PFTN (67 g/d) lambs. This finding agrees with a recent report indicating that heatstressed pigs had increased efficiency of converting dietary nutrients into body mass (Johnson et al., 2014). The obvious differences in growth performance between HS lambs and PFTN controls in our experiment and in others (Sanz Fernandez et al., 2012; Pearce et al., 2013; Mahjoubi et al., 2015) implies that HS markedly influences the energetics of tissue accretion. In contrast to our hypothesis, feeding a gluconeogenic precursor did not ameliorate the decreased ADG during HS. However, given the limited sample size in this study, investigating whether or not supplemental gluconeogenic precursors can increase growth in a larger experiment is of interest.

Regardless of measurement time, HS increased all body thermal indices compared with $\mathrm{TN}$ conditions, validating our HS model system. Surprisingly, the HSG lambs had decreased RT compared with the HSC lambs $\left(0.15 \pm 0.03^{\circ} \mathrm{C}\right.$ ) despite consuming more DMI (which likely increased basal heat production). The physiological importance of this small difference in body temperature, compared with a 0.7 to $0.8^{\circ} \mathrm{C}$ difference between HS lambs and TN lambs, is not clear, but the significant diet effect suggests there might be potential utility of nutritional strategies during HS. Increasing the provision of gluconeogenic precursors may lead to a decrease in the use of AA for gluconeogenesis and, in turn, increase energy and nitrogen use efficiency (Berg et al., 2007). This proposed mechanism is consistent with the decreased BUN in GLU-fed lambs in both thermal regimes (Table 3). In contrast, other nutritional strategies such as adding bypass protein (Bunting et al., 1992; Can et al., 2005) or supplemental fat (Caroprese et al., 2012) failed to affect core body temperature. It should be noted that the GLU product contained some niacin, and (although results vary) niacin has been shown to reduce body temperature in lactating heat-stressed cows (Zimbelman et al., 2010; Rungruang et al., 2014). However, niacin in the GLU product may have low bioavailability because it was not rumen protected (Campbell et al., 1994), and the dose used in the current experiment is less than $10 \%$ of what was fed to influence body temperature in the previous experiments (Zimbelman et al., 2010). Consequently, it is unlikely that niacin influenced body temperature indices in this study.

As we hypothesized, feeding GLU elevated postfeeding circulating glucose in HSG lambs but not in PFTNG lambs. In other words, compared with P1, HSC lambs had decreased postfeeding glucose concentrations whereas HSG lambs did not experience such a decrease (data not shown). There is inconsistency in the literature regarding the effects of similar products on circulating glucose concentrations. In our previous study (Hossein Yazdi et al., 2015) where heat-stressed bull calves were fed the same gluconeogenic product, we were unable to detect differences in postfeeding glucose concentration. The fact that PFTNG lambs did not have increased glucose concentration is probably because DMI was similar to that of PFTN lambs. Interpreting differences among studies is difficult, as several factors need to be considered, such as method of administration (drench vs. top-dressing), time of sampling in relation to time of supplementation, dose, and physiological status of the animal (Nielsen and Ingvartsen, 2004). For instance, Linke et al. (2004) showed that drenching glycerol can result in better performance compared with feeding glycerol in a total mixed ration.

In agreement with previous studies in sheep (Mahjoubi et al., 2015), steers (O'Brien et al., 2010), pigs (Pearce et al., 2013; Sanz Fernandez et al., 2015), and lactating cows (Itoh et al., 1998; Wheelock et al., 2010), prefeeding circulating insulin was increased in HS lambs compared with PFTN lambs. Postfeeding insulin concentrations, however, showed a reverse effect that was not expected. To our knowledge, there are no published data evaluating pre- and postfeeding circulating insulin in HS and PFTN lambs in a single study. It is very likely that the amount of time it took for the PFTN animals to eat their meal was much less than the HS lambs; therefore, they would be expected to have a more rapid increase in insulin (and likely other energetic variables) following the meal. Interestingly, and in agreement with the current experiment, Udum et al. (2008) showed that, under TN conditions, ad libitumfed lambs had lower postfeeding insulin concentration compared with lambs fed once or twice daily. Therefore, feed frequency (and feed restriction) likely has an effect on the postfeeding insulin response. Whatever the reason, GLU had no effect on prefeeding insulin concentration, which contradicted our previous study (Hossein Yazdi et al., 2015) where GLU increased prefeeding circulating insulin in Holstein bull calves.

Basal NEFA concentrations increased in PFTN (51\%) and HS (35\%) lambs compared with P1. Animals on a decreased plane of nutrition mobilize adipose tissue to compensate for energy insufficiency. This observation 
agrees with our previous sheep study (Mahjoubi et al., 2014) and other ovine reports (Sano et al., 1983; Sevi et al., 2001; Caroprese et al., 2012; Alhidary et al., 2012). Furthermore, the increased NEFA concentration in PFTN controls compared with HS animals replicates findings across species, as similar results have been reported in pigs (Pearce et al., 2013; Sanz Fernandez et al., 2015), steers (O'Brien et al., 2010), and lactating cattle (Wheelock et al., 2010; Baumgard et al., 2011). It is of interest to determine how much the increased adipose mobilization in the PFTN controls contributed to the decreased ADG compared with the HS lambs.

Heat-stressed animals increase their reliance on glucose as a systemic fuel. Nutritional strategies such as gluconeogenic precursor supplementation may alleviate the negative effects of HS. As expected, HS decreased DMI, but HSG lambs had greater DMI compared with HSC lambs. During P2, ADG was decreased, but it decreased much more dramatically in PFTN lambs than in HS lambs. Our results suggest that efficiency of converting dietary nutrients into tissue accretion was enhanced during HS. Although HS increased all thermal parameters, RT was slightly lower in HSG lambs than in HSC lambs during the afternoon measurement. In addition to steady circulating insulin parameters and minimal adipose tissue mobilization during HS, GLU decreased basal BUN and increased postfeeding glucose concentration. It should be noted again that the low number of animals in this experiment limit validity of performance data, so a larger experiment is warranted. Knowing whether or not the metabolic changes and improvements in thermal indices induced by GLU translate into meaningful production gains in larger commercial trials is important to the global animal agriculture industry.

\section{LITERATURE CITED}

Alhidary, I. A., S. Shini, R. A. M. Al Jassim, and J. B. Gaughan. 2012. Effect of various doses of injected selenium on performance and physiological responses of sheep to heat load. J. Anim. Sci. 90:2988-2994. doi:10.2527/jas.2011-4908

Allen, M. S., B. J. Bradford, and K. J. Harvatine. 2005. The cow as a model to study food intake regulation. Annu. Rev. Nutr. 25:523547. doi:10.1146/annurev.nutr.25.050304.092704

Ames, D. R., K. E. Nello, and T. Adams. 1971. Energy balance during heat stress in sheep. J. Anim. Sci. 32:784-788.

Aschenbach, J. R., N. B. Kristensen, S. S. Donkin, H. M. Hammon, and G. B. Penner. 2010. Gluconeogenesis in dairy cows: The secret of making sweet milk from sour dough. IUBMB Life 62:869-877. doi:10.1002/iub.400

Baumgard, L. H., and R. P. Rhoads. 2012. Ruminant Nutrition Symposium: Ruminant production and metabolic responses to heat stress. J. Anim. Sci. 90:1855-1865. doi:10.2527/jas.2011-4675

Baumgard, L. H., and R. P. Rhoads. 2013. Effects of heat stress on postabsorptive metabolism and energetics. Annu. Rev. Anim. Biosci. 1:311-337. doi:10.1146/annurev-animal-031412-103644
Baumgard, L. H., J. B. Wheelock, S. R. Sanders, C. E. Moore, and H. B. Green. 2011. Post-absorptive carbohydrate adaptations to heat stress and monensin supplementation in lactating Holstein cows. J. Dairy Sci. 94:5620-5633. doi:10.3168/jds.2011-4462

Berg, J. M., J. L. Tymoczko, and L. Stryer. 2007. Biochemistry. 6th ed. W. H. Freeman, New York, NY.

Bernabucci, U., N. Lacetera, L. H. Baumgard, R. P. Rhoads, B. Ronchi, and A. Nardone. 2010. Metabolic and hormonal acclimation to heat stress in domesticated ruminants. Animal 4:1167-1183. doi:10.1017/S175173111000090X

Bodarski, R., T. Wertelecki, F. Bommer, and S. Gosiewski. 2005. The changes of metabolic status and lactation performance in dairy cows under feeding TMR with glycerin (glycerol) supplement at periparturient period. Electron. J. Pol. Agric. Univ. 8:22-30.

Boyd, J., J. K. Bernard, and J. W. West. 2013. Effects of feeding different amounts of supplemental glycerol on ruminal environment and digestibility of lactating dairy cows. J. Dairy Sci. 96:470-476. doi:10.3168/jds.2012-5760

Buffington, D. E., A. Collazo-Arocho, G. H. Canton, D. Pitt, W. W. Thatcher, and R. J. Collier. 1981. Black globe-humidity index (BGHI) as comfort equation for dairy cows. Trans. ASAE 24:711-714. doi:10.13031/2013.34325

Bunting, L. D., L. S. Sticker, and P. J. Wozniak. 1992. Effect of ruminal escape protein and fat on nitrogen utilization in lambs exposed to elevated ambient temperatures. J. Anim. Sci. 70:1518-1525.

Campbell, J. M., M. R. Murphy, R. A. Christensen, and T. R. Overton. 1994. Kinetics of niacin supplements in lactating dairy cows. J. Dairy Sci. 77:566-575. doi:10.3168/jds.S00220302(94)76985-X

Can, A., N. Denek, and K. Yazgan. 2005. Effect of replacing urea with fish meal in finishing diet on performance of Awassi lamb under heat stress. Small Rumin. Res. 59:1-5. doi:10.1016/j.smallrumres.2004.10.008

Caroprese, M., M. Albenzio, A. Bruno, G. Annicchiarico, R. Marino, and A. Sevi. 2012. Effects of shade and flaxseed supplementation on the welfare of lactating ewes under high ambient temperature. Small Rumin. Res. 102:177-185. doi:10.1016/j.smallrumres.2011.07.010

DeFrain, J. M., A. R. Hippen, K. F. Kalscheur, and P. W. Jardon. 2004. Feeding glycerol to transition dairy cows: Effects on blood metabolites and lactation performance. J. Dairy Sci. 87:4195-4206. doi:10.3168/jds.S0022-0302(04)73564-X

Holtenius, P., and K. Holtenius. 2007. A model to estimate insulin sensitivity in dairy cows. Acta Vet. Scand. 49:29-31. doi:10.1186/1751-0147-49-29

Hossein Yazdi, M., H. Amanlou, H. R. Mirzaie-Alamouti, M. T. Harkinezhad, A. Nabipour, E. Mahjoubi, N. Aghaziarati, G. R. Noori, and L. H. Baumgard. 2015. Effects of a supplement containing multiple types of gluconeogenic precursors on production and metabolism in Holstein bull calves during heat stress. Livest. Sci. 178:61-70. doi:10.1016/j.livsci.2015.05.001

Huntington, G. B. 1990. Energy metabolism in the digestive tract and liver of cattle: Influence of physiological state and nutrition. Reprod. Nutr. Dev. 30:35-47. doi:10.1051/rnd:19900103

Iranian Council of Animal Care. 1995. Guide to the care and use of experimental animals, Vol. 1. Isfahan University of Technology, Isfahan, Iran.

Itoh, F., Y. Obara, M. T. Rose, H. Fuse, and H. Hashimoto. 1998. Insulin and glucagon secretion in lactating cows during heat exposure. J. Anim. Sci. 76:2182-2189. 
Johnson, J. S., M. V. Sanz Fernadez, J. F. Patience, J. W. Ross, N. K. Gabler, M. C. Lucy, T. J. Sanfranski, R. P. Rhoads, and L. H. Baumgard. 2014. In utero heat stress alters body composition during the early finishing phase (60 to $80 \mathrm{~kg}$ ) in pigs. J. Anim. Sci. 92(Suppl. 2):54.

Kadzere, C. T., M. R. Murphy, N. Silanikove, and E. Maltz. 2002. Heat stress in lactating dairy cows: A review. Livest. Prod. Sci. 77:59-91. doi:10.1016/S0301-6226(01)00330-X

Kleiber, M. 1961. The fire of life. John Wiley \& Sons, New York, NY.

Linke, P. L., J. M. DeFrain, A. R. Hippen, and P. W. Jardon. 2004. Ruminal and plasma responses in dairy cows to drenching or feeding glycerol. J. Dairy Sci. 87:343. (Abstr.)

Mahjoubi, E., N. Aghaziarati, M. Hossein Yazdi, G. R. Noori, O. Afsarian, and L. H. Baumgard. 2015. The effect of cyclical and severe heat stress on productive performance and metabolism in Afshari lambs. J. Anim. Sci. 93:1632-1640. doi:10.2527/ jas.2014-8641

Mahjoubi, E., H. Amanlou, H. R. Mirzaie-Alamouti, N. Aghaziarati, M. Hossein Yazdi, G. R. Noori, K. Yuan, and L. H. Baumgard. 2014. The effect of cyclical and mild heat stress on productivity and metabolism in Afshari lambs. J. Anim. Sci. 92:1007-1014. doi:10.2527/jas.2013-7153

Nielsen, N. I., and K. L. Ingvartsen. 2004. Propylene glycol for dairy cows. A review of the metabolism of propylene glycol and its effects physiological parameters, feed intake, milk production and risk of ketosis. Anim. Feed Sci. Technol. 115:191-213. doi:10.1016/j.anifeedsci.2004.03.008

NRC. 2007. Nutrient requirements of small ruminants: Sheep, goats, cervids, and new world camelids. Natl. Acad. Press, Washington, DC.

O’Brien, M. D., R. P. Rhoads, S. R. Sanders, G. C. Duff, and L. H. Baumgard. 2010. Metabolic adaptations to heat stress in growing cattle. Domest. Anim. Endocrinol. 38:86-94. doi:10.1016/j. domaniend.2009.08.005

Pearce, S. C., N. K. Gabler, J. W. Ross, J. Escobar, J. F. Patience, R. P. Rhoads, and L. H. Baumgard. 2013. The effects of heat stress and plane of nutrition on metabolism in growing pigs. J. Anim. Sci. 91:2108-2118. doi:10.2527/jas.2012-5738

Rungruang, S., J. L. Collier, R. P. Rhoads, L. H. Baumgard, M. J. de Veth, and R. J. Collier. 2014. A dose-response evaluation of rumen-protected niacin in thermoneutral or heat-stressed lactating Holstein cows. J. Dairy Sci. 97:5023-5034. doi:10.3168/ jds.2013-6970

Russell, K. E., and A. J. Roussel. 2007. Evaluation of the ruminant serum chemistry profile. Vet. Clin. North Am. Food Anim. Pract. 23:403-426. doi:10.1016/j.cvfa.2007.07.003
Sano, H., K. Takahashi, K. Ambo, and T. Tsuda. 1983. Turnover and oxidation rates of blood glucose and heat production in sheep exposed to heat. J. Dairy Sci. 66:856-861. doi:10.3168/jds. S0022-0302(83)81867-0

Sanz Fernandez, M. V., J. S. Johnson, M. Abuajamieh, S. K. Stoakes, J. T. Seibert, L. Cox, S. Kahl, T. H. Elsasser, J. W. Ross, S. C. Isom, R. P. Rhoads, and L. H. Baumgard. 2015. Effects of heat stress on carbohydrate and lipid metabolism in growing pigs. Physiol. Rep. 3:e12315. doi:10.14814/phy2.12315

Sanz-Fernandez, M. V., S. C. Pearce, L. R. Long, N. K. Gabler, J. F. Patience, M. E. Wilson, J. Torrison, M. T. Socha, R. P. Rhoads, and L. H. Baumgard. 2012. Effects of supplemental zinc amino acid complex on physiology and performance in heat-stressed growing pigs. J. Anim. Sci. 90:312. (Abstr.)

Sevi, A., G. Annicchiarico, M. Albenzio, L. Taibi, A. Muscio, and S. Dell'Aquila. 2001. Effects of solar radiation and feeding time on behavior, immune response and production of lactating ewes under high ambient temperature. J. Dairy Sci. 84:629-640. doi:10.3168/jds.S0022-0302(01)74518-3

Tedeschi, L. O., A. Cannas, and D. G. Fox. 2010. A nutrition mathematical model to account for dietary supply and requirements of energy and other nutrients for domesticated small ruminants: The development and evaluation of the Small Ruminant Nutrition System. Small Rumin. Res. 89:174-184. doi:10.1016/j. smallrumres.2009.12.041

Terrill, C. E., and J. Slee. 1991. Breed differences in adaptation of sheep. In: K. Maijala, editor, Genetic resources of pig, sheep and goat. Elsevier Science Publishers, Amsterdam, Netherlands. p. 195-233.

Udum, C. D., M. Cetin, F. Balci, N. Gunes, and C. Hecer. 2008. Effects of plasma insulin, glucose and NEFA concentrations of feeding frequency during long term in lambs. J. Biol. Environ. Sci. 2:45-51.

West, J. W. 1999. Nutritional strategies for managing the heat-stressed dairy cow. J. Dairy Sci. 77(Suppl. 2):21-35.

Wheelock, J. B., R. P. Rhoads, M. J. Vanbaale, S. R. Sanders, and L. H. Baumgard. 2010. Effects of heat stress on energetic metabolism in lactating Holstein cows. J. Dairy Sci. 93:644-655. doi:10.3168/jds.2009-2295

Zimbelman, R. B., L. H. Baumgard, and R. J. Collier. 2010. Effects of encapsulated niacin on evaporative heat loss and body temperature in moderately heat-stressed lactating Holstein cows. J. Dairy Sci. 93:2387-2394. doi:10.3168/jds.2009-2557 